\title{
Challenges, Barriers, and Good Practices in the Implementation of Rashtriya Bal Swasthya Karyakram in Jodhpur, India
}

\author{
Niraj Kumar ${ }^{1}$ Nitin Kumar Joshi ${ }^{1} \quad$ Yogesh Kumar Jain ${ }^{1, \odot} \quad$ Kuldeep Singh ${ }^{1} \quad$ Pankaj Bhardwaj ${ }^{2}$ \\ Praveen Suthar ${ }^{1} \quad$ Balwant Manda ${ }^{3} \quad$ Ravi Kirti $^{4}$
}

${ }^{1}$ School of Public Health, All India Institute of Medical Sciences, Jodhpur, Rajasthan, India

${ }^{2}$ Department of Community Medicine and Family Medicine, School of Public Health, All India Institute of Medical Sciences, Jodhpur, Rajasthan, India

${ }^{3}$ Chief Medical and Health Officer, Jodhpur, Rajasthan, India

${ }^{4}$ District Early Intervention Centers, Rashtriya Bal Swasthya

Karyakram, Jodhpur, Rajasthan, India

\begin{abstract}
Address for correspondence Pankaj Bhardwaj, MBBS, MD, Department of Community Medicine and Family Medicine, School of Public Health, All India Institute of Medical Sciences, Basni Phase-II, Jodhpur, Rajasthan 342 005, India

(e-mail: pankajbhardwajdr@gmail.com).
\end{abstract}

Ann Natl Acad Med Sci (India) 2021;57:237-243.

\begin{abstract}
Introduction The Rashtriya Bal Swasthya Karyakram of the Government of India subsumes the existing school health program to provide care and treatment to children below 18 years through screening and early interventions. Benefitting an estimated 270 million children for 30 preidentified conditions is a step toward "health for all." Although the program is running since 2013, due to paucity of studies particularly in Thar desert region and its associated challenges, this study was planned to assess challenges and good practices in the implementation of RBSK in Jodhpur.

Objectives To assess the challenges, barriers, and good practices in the implementation of RBSK among the mobile health team (MHT) in Jodhpur, Rajasthan.

Methods A community based descriptive cross-sectional study in all 11 medical blocks of Jodhpur district, with purposive sampling to invite all members of MHT to participate in the study as grassroot workers was planned. A pretested, semistructured questionnaire was processed using SPSS for quantitative component and in-depth interviews were reported using qualifiers for qualitative observations.

Results As much as $74.1 \%(n=40)$ of the staff perceived the trainings to be sufficient for daily work needs but needed more sessions for birth defects (33.3\%) and development delays $(29.6 \%)$. As much as $96.3 \%(n=52)$ of the staff considered salaries to be low and $55.5 \%$ were dissatisfied with the jobs. However, $70.4 \%$ found targets to be

Keywords

- RBSK

- challenges

- barriers

- implementation

- Rajasthan achievable and $76 \%$ found the work environment helpful. Taboos and superstitions in community, harsh climate, dual workload on pharmacists as data operators, and noninclusion of AYUSH medicines for AYUSH medical officers (MOs) were few of the challenges, while good practices such as fully equipped MHTs, readily available vehicles, information education communication (IEC) materials, and treatment coverage under Bhamashah Bima Yojana (BSBY) were also observed.
\end{abstract}

published online October 26, 2021
DOI https://doi.org/ $10.1055 / \mathrm{s}-0041-1739032$ ISSN 0379-038X (c) 2021. National Academy of Medical Sciences (India).

This is an open access article published by Thieme under the terms of the Creative Commons Attribution-NonDerivative-NonCommercial-License, permitting copying and reproduction so long as the original work is given appropriate credit. Contents may not be used for commercial purposes, or adapted, remixed, transformed or built upon. (https://creativecommons.org/licenses/by-nc-nd/4.0/).

Thieme Medical and Scientific Publishers Pvt. Ltd. A-12, 2nd Floor, Sector 2, Noida-201301 UP, India 
Conclusion Many good practices were observed during the study which can be adopted by other states for better implementations elsewhere. Certain challenges such as belief in quackery, superstitions and taboos could be minimized by conducting rapport-building meetings with community stakeholders. Feedback and regular trainings of MHT staff can further increase the success manifold.

\section{Introduction}

The Rashtriya Bal Swasthya Karyakram (RBSK) is an innovative and ambitious initiative of the Ministry of Health and Family Welfare, Government of India. ${ }^{1}$ Launched under the National Health Mission, this initiative subsumes the existing school health program and envisions child health screening and early intervention services to provide care, support, and treatment to children. ${ }^{2}$ Child health screening and early intervention services refer to early detection and management of a set of 30 preidentified health conditions such as birth defects, deficiency conditions, and developmental delays including disabilities (4Ds) that are prevalent in children of less than 18 years of age. ${ }^{3}$

In India, out of every 100 live births, 6 to 7 have birth defects, which translate to 1.7 million birth defects annually and lead to $9.9 \%$ of all newborn deaths. ${ }^{456}$ Development delays are common in early childhood, affecting at least 10\% of the children. ${ }^{7}$ If not intervened in a timely manner, these delays may lead to permanent disabilities, resulting in cognition imbalance and hearing and vision disabilities. ${ }^{8910}$ With an aim to reduce the extent of disability and improve the quality of life through health screening and early interventions, this program is aimed to be a step toward "health for all," benefitting an estimated 270 million children between age of 0 to 18 years attending Anganwadi centers and government schools. ${ }^{9}$

Although the RBSK program has been running in the country since 2013, there is a paucity of studies on RBSK, particularly in this part of the country, which comes in with the additional challenges associated with the remotely located areas of the Thar desert. Moreover, the few studies that have been conducted in the context of RBSK are only knowledge, attitudes and beliefs, and practices (KAP) based. It is evident from these studies that the health team deployed under any project or program faces varied challenges and barriers related to the work conditions such as cooperation, support, resistance from community, and burden of work. ${ }^{11213}$

The task taken up in the program is quite enormous but possible nevertheless. Only through a systematic approach and implementation, rich dividends in protecting and promoting the health of the children can be achieved.

Challenges and barriers affect the progress of any program, and if these factors are identified, then measures could be planned to overcome them for betterment. Every program has some good practices as well, which reveal the progress of the program, and are necessary to be identified, as these could be adopted ubiquitously for the beneficence of the beneficiaries and providers.

Keeping the above in mind, this study was planned to assess the challenges, barriers, and good practices in implementation of RBSK program.

\section{Objectives}

- To assess the challenges and barriers for implementation of RBSK among the mobile health team (MHT) in Jodhpur.

- To assess the good practices for implementation of RBSK among the MHT in Jodhpur

\section{Methods}

A community-based descriptive cross-sectional study was planned in 11 medical blocks of Jodhpur district of Rajasthan, India. The MHT was taken as primary unit of study, since an MHT works at the grassroot level for the implementation of this program.

Purposive sampling was used and all the members of the MHT of all 11 medical blocks were invited to participate in the study. Ayurveda, Yoga and Naturopathy, Unani, Siddha and Homeopathy (AYUSH) medical officers, auxiliary nurse midwives (ANMs), and pharmacists of the MHT were included, and those who were on maternity, casual or medical leaves were excluded.

For the quantitative component, a semistructured questionnaire was used, based on the formative research report of RBSK, Assam, while for the qualitative component, in-depth interviews of the members of MHT were conducted. The questionnaire comprised questions related to manpower, sociodemographic information, perception regarding trainings, support and resistance from officials and community, and challenges faced by the teams. The data collection was done at the time of visit to individual blocks by the interviewer, and data pertaining to the manpower, equipment, transport facilities and good practices were noted through observations. Data related to satisfaction, perception about trainings, resistance from community, and support from the officials were recorded along with the demographic details from all the staff members present on the day of visit through the interviews and questionnaire. Quantitative data was processed using SPSS software and qualitative observation were presented in semiquantitative form using qualifiers. 


\section{Results and Observations}

Under the RBSK program, children of age 6 to 18 years are screened in government and government-aided schools, with the block serving as the hub of all activities, and villages in the jurisdiction of the block distributed among the MHTs. At least three dedicated MHTs in each block were engaged to conduct the screening, and the number of teams varied, depending upon the number of Anganwadi centers, remoteness and number of children enrolled in the schools.

Every MHT is composed of 2 AYUSH medical officers ( 1 male and 1 female), 1 ANM or staff nurse, and 1 pharmacist having proficiency in computers for additional task of data management. Screening was found to be conducted at least twice a year in children enrolled in Anganwadi centers and at least once a year for school children.

A toolkit with essential equipment for screening of children was provided to the MHT members, including equipment for screening of development delays: bell, rattle, torch, one-inch cubes, bottle with resins, squeaky toys and colored wool (for 6 weeks-6 years) and vision charts, reference charts, blood pressure (BP) apparatus with age-appropriate cuffs (for 6 years-18 years). Age-appropriate anthropometry equipment such as weighing scales, height-measuring stadiometers, and tapes and bangles for midarm circumference and head circumference were also found along with a development checklist to record milestones for identification of developmental delays. Vehicles were hired for movement to different locations (Anganwadi centers, government and government-aided schools).

Every MHT prepared a microplan prior to a visit to Anganwadi and schools, considering route chart for daywise visits, logistics management, reporting system, and identification of all relevant stakeholders.

The in charge medical officer (MO) of the block takes the lead in the microplanning process and is supported by members of the mobile team and local health staff. In urban areas, the district chief MO designates a nodal hospital/dispensary with a key-in-charge staff for overseeing the activities and preparing microplans related to RBSK.

\section{Socio Demographic Information}

Out of the total participants $(n=54)$ surveyed from 11 medical blocks of Jodhpur, 44 were female, and majority of participants (57.4\%) were of age group between 30 to 40 years in this survey. Among all participants, there were 32 medical officers, 11 ANMs, and 11 pharmacists. Mean salary of the MOs, ANMs, and pharmacists were Rs. 17,061 \pm 374.51 , Rs. 6,075 \pm 386.70 , and Rs. 8,314 \pm 412.61 , respectively (-Table $\mathbf{1}$ ).

Challenges and Barriers Faced by the Members of MHTs Majority of the MOs $(90.6 \% ; n=29)$ agreed that training provided to them through RBSK was sufficient to carry out the screening activities and overcome the field challenges, while only $36.4 \%(n=4)$ of ANMs agreed with the same. On the other hand, all MOs $(n=32)$ and pharmacists $(n=11)$ considered that their salary was not in accordance with the designation and workload. MHT staff agreed that more training sessions were required for screening and management of issues related to defects at birth and development delays and disabilities (- Table 2).

As much as $78.1 \%$ of the MOs and $72.7 \%$ ANMs perceived the targets provided to them to be achievable, but the perception was not so among the pharmacists, $54.5 \%$ of whom considered the targets to be unachievable.

Most of the MOs (62.5\%) and pharmacists (72.8\%) did not seem satisfied with their job, whereas $81.8 \%$ ANMs were found to be satisfied; $75 \%$ MOs, $90.9 \%$ ANMs and $63.6 \%$ pharmacists perceived the work atmosphere at screening camp helpful and mutually cooperative. Nevertheless, majority of the MHT staff (68.8\% MO, 63.6\% ANMs and 63.6\% pharmacists) shared experiences of facing resistance from the community during screening camps.

Other challenges that were brought forward during the interviews were those of harsh climatic conditions, difficult terrain and inaccessible areas, and prevalence of superstitions among villagers and tribes.

Adverse working conditions:

"Most of the time during our work, temperature is too high."

"Areas adjacent to the Thar desert have extremely high temperatures, which do not allow us to work with full potential."

Superstitions and local practices:

Caregivers were reported to be not ready for treatment of their children even when the government provided it free of cost; instead, they made different excuses and were reluctant for availing treatment or suggestions provided by the RBSK team.

"Superstition prevails among the villagers at various levels, few villagers think that tantriks can treat disease better than the doctors, they consider everything (deeds and spirits) and not just our illness."

Table 1 Showing demographic characteristics of the participants surveyed from 11 medical blocks of Jodhpur

\begin{tabular}{|l|l|l|}
\hline Characteristics & $\boldsymbol{n}=\mathbf{5 4}$ & $\%$ \\
\hline Age & 19 & 35.19 \\
\hline $20-30$ & 31 & 57.41 \\
\hline $30-40$ & 4 & 7.40 \\
\hline 40 -above & 30 & 55.46 \\
\hline Gender & 44.44 \\
\hline Male & 24 & 59.3 \\
\hline Female & 32 & 20.4 \\
\hline Post Profile & 11 & 20.4 \\
\hline MO & 11 & \\
\hline ANM &
\end{tabular}

Abbreviations: ANM, auxiliary nurse midwife; MO, medical officer. 
Table 2 Showing perception of participants regarding various issues

\begin{tabular}{|c|c|c|c|c|c|}
\hline & & \multicolumn{3}{|c|}{ MHT staff } & \multirow{2}{*}{$\begin{array}{l}\text { Total } \\
(n=54)\end{array}$} \\
\hline & & $\begin{array}{l}\mathrm{MO} \\
(n=32)\end{array}$ & $\begin{array}{l}\text { ANM } \\
(n=11)\end{array}$ & $\begin{array}{l}\text { Pharmacist } \\
(n=11)\end{array}$ & \\
\hline \multirow{5}{*}{$\begin{array}{l}\text { Perception regarding } \\
\text { RBSK training fulfill- } \\
\text { ing daily work needs }\end{array}$} & $\begin{array}{l}\text { Strongly agree } \\
\%(n)\end{array}$ & 28.1 (9) & $0(0)$ & $18.2(2)$ & $20.4(11)$ \\
\hline & $\begin{array}{l}\text { Agree } \\
\%(n)\end{array}$ & $62.5(20)$ & $36.4(4)$ & $45.5(5)$ & 53.7 (29) \\
\hline & $\begin{array}{l}\text { Neutral } \\
\%(n)\end{array}$ & $3.1(1)$ & $18.2(2)$ & $9.1(1)$ & $7.4(4)$ \\
\hline & $\begin{array}{l}\text { Disagree } \\
\%(n)\end{array}$ & $3.1(1)$ & $27.3(3)$ & $18.2(2)$ & $11.1(6)$ \\
\hline & $\begin{array}{l}\text { Strongly Disagree } \\
\%(n)\end{array}$ & $3.1(1)$ & $18.2(2)$ & $9.1(1)$ & $7.4(4)$ \\
\hline \multirow{5}{*}{$\begin{array}{l}\text { Perception regarding } \\
\text { need for more } \\
\text { training session for } \\
\text { different diseases }\end{array}$} & $\begin{array}{l}\text { Defects at birth } \\
\%(n)\end{array}$ & $37.5(12)$ & $27.3(3)$ & $27.3(3)$ & $33.3(18)$ \\
\hline & $\begin{array}{l}\text { Deficiencies } \\
\%(n)\end{array}$ & $9.4(3)$ & $0(0)$ & $0(0)$ & $5.6(3)$ \\
\hline & $\begin{array}{l}\text { Childhood disease } \\
\%(n)\end{array}$ & $18.8(6)$ & $0(0)$ & $9.1(1)$ & $13(7)$ \\
\hline & $\begin{array}{l}\text { Development delays and } \\
\text { disabilities \% ( } n)\end{array}$ & $31.3(10)$ & $18.2(2)$ & $36.4(4)$ & $29.6(16)$ \\
\hline & $\begin{array}{l}\text { Others } \\
\%(n)\end{array}$ & $3.1(1)$ & $54.5(6)$ & $27.3(3)$ & 18.5 (10) \\
\hline \multirow{3}{*}{$\begin{array}{l}\text { Perception of } \\
\text { respondents regard- } \\
\text { ing salary }\end{array}$} & $\begin{array}{l}\text { Satisfactory } \\
\%(n)\end{array}$ & $0(0)$ & $18.2(2)$ & $0(0)$ & $3.7(2)$ \\
\hline & $\begin{array}{l}\text { Unsatisfactory } \\
\%(n)\end{array}$ & $81.3(26)$ & $36.4(4)$ & $63.6(7)$ & $68.5(37)$ \\
\hline & $\begin{array}{l}\text { Very low } \\
\%(n)\end{array}$ & $18.8(6)$ & $45.5(5)$ & $36.4(4)$ & $27.8(15)$ \\
\hline \multirow{4}{*}{$\begin{array}{l}\text { Perception regarding } \\
\text { job satisfaction and } \\
\text { future prospects }\end{array}$} & $\begin{array}{l}\text { Stay in same job } \\
\%(n)\end{array}$ & $6.3(2)$ & $27.3(3)$ & $18.2(2)$ & $13(7)$ \\
\hline & $\begin{array}{l}\text { Job is promising } \\
\%(n)\end{array}$ & $31.3(10)$ & $54.5(6)$ & $9.1(1)$ & $31.5(17)$ \\
\hline & $\begin{array}{l}\text { Dissatisfied } \\
\%(n)\end{array}$ & $46.9(15)$ & $18.2(2)$ & $45.5(5)$ & $40.7(22)$ \\
\hline & $\begin{array}{l}\text { Leave as soon as possible } \\
\%(n)\end{array}$ & $15.6(5)$ & $0(0)$ & $27.3(3)$ & $14.8(8)$ \\
\hline \multirow[t]{3}{*}{$\begin{array}{l}\text { Perception regarding } \\
\text { provided targets }\end{array}$} & $\begin{array}{l}\text { Achievable } \\
\%(n)\end{array}$ & $78.1(25)$ & $72.7(8)$ & $45.5(5)$ & $70.4(38)$ \\
\hline & $\begin{array}{l}\text { Not achievable } \\
\%(n)\end{array}$ & $18.8(6)$ & $27.3(3)$ & $54.5(6)$ & $27.8(15)$ \\
\hline & $\begin{array}{l}\text { Achievable but quality } \\
\text { suffers } \\
\%(n)\end{array}$ & $3.1(1)$ & $0(0)$ & $0(0)$ & $1.9(1)$ \\
\hline \multirow{3}{*}{$\begin{array}{l}\text { Perception about } \\
\text { atmosphere at } \\
\text { screening camp }\end{array}$} & $\begin{array}{l}\text { Helpful } \\
\%(n)\end{array}$ & $75(24)$ & $90.9(10)$ & $63.6(7)$ & $76(41)$ \\
\hline & $\begin{array}{l}\text { Neutral } \\
\%(n)\end{array}$ & $12.5(4)$ & $9.1(1)$ & $27.3(3)$ & $14.8(8)$ \\
\hline & $\begin{array}{l}\text { Noncooperative } \\
\%(n)\end{array}$ & $12.5(4)$ & $0(0)$ & $9.1(1)$ & $9.3(5)$ \\
\hline \multirow{3}{*}{$\begin{array}{l}\text { Perception about } \\
\text { resistance from } \\
\text { community }\end{array}$} & $\begin{array}{l}\text { Always } \\
\%(n)\end{array}$ & $0(0)$ & $9.1(1)$ & $0(0)$ & $1.9(1)$ \\
\hline & $\begin{array}{l}\text { Sometimes } \\
\%(n)\end{array}$ & $68.8(22)$ & $54.5(6)$ & $63.6(7)$ & $64.8(35)$ \\
\hline & $\begin{array}{l}\text { Not at all } \\
\%(n)\end{array}$ & $31.3(10)$ & $36.4(4)$ & $36.4(4)$ & $33.3(18)$ \\
\hline
\end{tabular}

Abbreviations: ANM, auxiliary nurse midwife; MHT, mobile health team; MO, medical officer. 
"Diseases and deformities, according to the rural caregivers, is a curse of their past life deeds"

\section{Manpower:}

Certain MHTs reported to be deficient in human resources and thus unable to meet targets repeatedly.

"We do not have sufficient manpower required for our block size, so we are missing deadlines repeatedly."

"We have MOs but not sufficient data entry operators and nurses, so our reporting is often delayed."

Transport facilities:

Proper roads for transportation seemed to be lacking in most of the remote villages, and the RBSK team considered it to be one of the major issues against reaching out to maximum population.

"Sometimes, team needs to walk a long distance to reach remotely located Anganwadi centers and schools."

"Many times, RBSK vehicles cannot cross difficult terrains, and we have to walk to reach our destination."

Support from Anganwadi centers:

In some instances, support from Anganwadi center was lacking. In such Anganwadis, attendance of children was low during the screening camp.

"Few Anganwadi workers do not take interest in RBSK program, and when forced, they bring unregistered children to increase the attendance at RBSK screening camp."

Salary and renumeration:

While taking in-depth interviews, most of the MOs had concerns about their salary.

"Our salary is very low as compared to other states' RBSK Mos."

"Considering the workload, salary should be similar to permanent MOs."

AYUSH medicines:

Majority of MOs were of view that AYUSH medicine should be incorporated in medicine kit, as MHT MOs were from AYUSH background.

"AYUSH medicine are very effective in childhood diseases and should be provided along with allopathy."

"Authorities should provide provision of AYUSH system of medicines in the medicine kit."

\section{Good Practices}

Along with the challenges and barriers, certain good practices were also observed in the implementation of RBSK by various MHTs during the course of study, such as fully functional and adequately equipped MHTs of RBSK Jodhpur along with appropriate vehicles that were readily available and maintained prior to every field visit. Most of the MHTs were found to be able in providing information education communication (IEC) for creating awareness during screening camps related to newborn diseases and healthy lifestyles.

In the state of Rajasthan, Bhamashah Bima Yojana (BSBY) covers RBSK surgical cost of the patient, which was found to be able to provide for better patient compliance, coverage and acceptability. At the level of data collection, most of the screened data was sent to the district early intervention center (DEIC) through an online portal, which made the data entry transparent and rapid with limited errors.

\section{Discussion}

The RBSK project was launched in February 2013 with the objectives of early detection and management of the 4Ds, and in this study, we tried to assess challenges, barriers, and good practices in center so far toward achieving this objective of RBSK in Jodhpur, Rajasthan.

It was evident in this study that RBSK team is getting supportive environment for their work in communities, but myths and misconceptions of the rural community were posing major challenges to their functioning. Education and sensitization with reinforcement could help to overcome this barrier.

In the present study, findings revealed that MHT of medical block (Baap, Phalodi, and Balesar) were deficient in human resources required to complete the target. Most of the medical officers were from Ayurvedic (Bachelor of Ayurvedic Medicine and Surgery [BAMS]) background and a few from other streams (Bachelor of Homeopathic Medicine and Surgery [BHMS], Bachelor of Unani Medicine and Surgery [BUMS]), but there was a deficiency of data entry operator and nurses. Similar findings were highlighted in the study conducted by Singh et al. ${ }^{14}$

The challenges, barriers, and good practices of all MHTs of RBSK were assessed using a pretested questionnaire, and majority of MOs agreed that the training provided by RBSK fulfils the basic need of organizing screening camps.

It was found in the study that RBSK was successful in maintaining the satisfaction level of grassroot level team worker (ANMs), but a contrast was observed in context of the salaries in the perception of majority of MOs and pharmacists. The salaries were considered very low compared with other states where RBSK program is running. Most of the pharmacists thought that work target provided to them were not achievable, because they had dual roles of work as a pharmacist as well as that of a data entry operator. Similar challenges were reported in the implementation of other national programs in the country, as highlighted by the studies conducted by Sogarwal et al and Best and Kumar. ${ }^{15,16}$ 
Most of the MOs, pharmacists, and ANMs perceived that atmosphere at screening camp was helpful. However, sometimes, resistance was created by community, and seldom by school teachers and Anganwadi staff, which affected the screening program. Furthermore, most of the MOs faced challenges while convincing caregivers of the children, because of prevailing superstitions among the villagers, which posed a major barrier in implementation. Rural caregivers said that diseases are a curse of their past lives' deeds, and they seemed reluctant to avail treatment or suggestions provided by the RBSK team. Similar challenges in health seeking behaviors were observed in studies conducted by Sagar et al and Kaur et al. ${ }^{17,18}$

Findings from the present study revealed that majority of MOs viewed that AYUSH medicine should be incorporated in medicinal kit, as MHT MOs were from AYUSH background, and they perceived that AYUSH medicines are very effective in childhood diseases.

While certain good practices such as fully occupied MHTs of RBSK Jodhpur with screening equipment, availability of appropriate vehicles for field visits, and ANMs perceived to be satisfied with their job were seen, nevertheless most of the MOs and pharmacists were not satisfied with their jobs. It may be due to the fact that majority of MOs and pharmacists considered that their salary was very low compared with other states running RBSK program.

\section{Conclusion and Recommendations}

With this study, we inferred that the certain good practices as well as many challenges were major determinants in the achievement of objectives of the ongoing RBSK program. Lesser salary and dual workload for pharmacists were major barriers which along with challenges such as harsh weather conditions, poor terrain, and resistance created by local community hindered the working up to full potential by the MHT staff. There is a requirement of more training sessions on birth defects, and issues such as lack of manpower in certain blocks need to be addressed.

Through the study, few systematic recommendations are suggested, which if implied might prove to improve program implementation. There is a need for an equality in the wages of MHT staff in comparison with other RBSK running states and a need for rapport-building activities with community stakeholders prior to the scheduled screening. Awareness activities for the community with major involvement of local stakeholders would be helpful in reducing the community resistance experienced by MHT staff. Recruitment of dedicated data entry operators, responsible for data entry of a group of MHTs, would further increase the efficiency of the pharmacists while not straining the budgetary restraints. Provision of AYUSH medicines in the medicine kit to be used along with allopathic treatment modalities, provision of air condition vehicles to combat the harsh weather conditions, and frequent feedback from MHT staff regarding training requirements and regular training activities regarding the same are further expected to increase staff compliance and ensure program success.

\section{Conflict of Interest}

None declared.

\section{Acknowledgment}

We thank the offices of Chief Medical \& Health Officer, Joint Director Medical \& Health Services, Reproductive \& Child Health and Urban Health Planning Consultant of Jodhpur, Rajasthan, for their invaluable support. Without their help, this project would not have completed successfully.

\section{References}

1 National Health Portal of India. Rashtriya Bal Swasthya Karyakram (RBSK). Available at: https://www.nhp.gov.in/ rashtriya-bal-swasthyakaryakram-(rbsk)_pg. Accessed July 23, 2020

2 Ministry of Health and Family Welfare. Government of India. Review of Performance Chapter IV. Available at: https://main. mohfw.gov.in/sites/default/files/Review_of_Performance.pdf. Accessed July 23, 2020

3 Rashtriya Bal Swasthya Karyakram. Ministry of Heallth \& Family Welfare, Government of India. Available at: https:// rbsk.gov.in/RBSKLive/. Accessed July 14, 2020

4 March of Dimes Birth Defects Foundation. Global Report on Birth defects. Available at: https://www.marchofdimes.org/ global-report-on-birth-defects-the-hidden-toll-of-dyingand-disabled-children-full-report.pdf. Accessed July 14, 2020

5 Sharma R. Birth defects in India: hidden truth, need for urgent attention. Indian J Hum Genet 2013;19(2):125-129

6 Bhide P, Gund P, Kar A. Prevalence of congenital anomalies in an indian maternal cohort: healthcare, prevention, and surveillance implications. PLoS One 2016;11(11):e0166408

7 Sharma N, Masood J, Singh SN, et al. . Assessment of risk factors for developmental delays among children in a rural community of North India: a cross-sectional study. J Educ Health Promot 2019;8:112

8 World Health Organization. Regional Office for SouthEast Asia. (2013). Birth defects in South-East Asia: a public health challenge: situation analysis. WHO Regional Office for South-East Asia. Available at: https://apps.who.int/iris/ handle/10665/204821

9 Ministry of Health \& Family Welfare. Government of India. Operational Guidelines Rashtriya Bal Swasthya Karyakram (RBSK). Child Health Screening and Intervention Services under NRHM. Available at: https://nhm.gov.in/images/pdf/ programmes/RBSK/Operational_Guidelines/Operational\%20 Guidelines_RBSK.pdf. Accessed July 15, 2020

10 Marrus N, Hall L. Intellectual disability and language disorder. Child Adolesc Psychiatr Clin N Am 2017;26(3):539-554

11 Deloitte Touche Tohmatsu India LLP. UNICEF. Formative Research Report on RBSK. From Survical to Healthy Survival. Available at: https://nhm.assam.gov.in/sites/default/files/ swf_utility_folder/departments/nhm_lipl_in_oid_6/menu/ schemes/Formative_Research_Report_on_RBSK.pdf. Accessed July 182020

12 Parmar S, Bansal S, Raghunath D, Patidar A. Study of knowledge, attitude and practice of AYUSH doctors, evaluation of MHTs working in RBSK and client satisfaction. Int J Community Med Publ Health 2017;3(8):2186-2190

13 Parmar S, Raghunath D, Dixit S, Bansal SB, Patidar A. A cross-sectional study to evaluate the functioning and 
infrastructure of DEIC, and client satisfaction Ujjain and Indore districts established under RBSK. IOSR J Dent Med Sci 2016;5(9):92-94

14 Singh AK, Kumar R, Mishra CK, Khera A, Srivastava A. Moving from survival to healthy survival through child health screening and early intervention services under Rashtriya Bal Swasthya Karyakram (RBSK. Indian J Pediatr 2015;82(11):1012-1018

15 Sogarwal R, Bachani D, Venkatesh S. Challenges in HIV/AIDS prevention, care and treatment programme in India. SAARC J Tuberc Lung Dis HIV/AIDS 2010;7(1):1-7
16 Best ML, Kumar R. Sustainability failures of rural telecenters: challenges from the sustainable access in rural India (SARI) project. Inf Technol Int Dev 2008;4(4):31-45

17 Sagar R, Pattanayak RD, Chandrasekaran R, et al.. Twelve-month prevalence and treatment gap for common mental disorders: Findings from a large-scale epidemiological survey in India. Indian J Psychiatry 2017;59(1):46-55

18 Kaur S, Thapar K, Saini P, Kaur H, Kaur J. Myths \& misconceptions of mental illness and health seeking behaviour of adults. Int J Com Health and Med Res 2016;2(3):3-9 